\title{
TEMPAT RELAKSASI DI MERUYA
}

\author{
Bervianda ${ }^{1)}$, Franky Liauw ${ }^{2}$ \\ 1)Program Studi S1 Arsitektur, Fakultas Teknik, Universitas Tarumanagara, bervianda25@gmail.com \\ 2)Program Studi S1 Arsitektur, Fakultas Teknik, Universitas Tarumanagara, frankyl@ft.untar.ac.id
}

\begin{abstract}
Abstrak
Masyarakat kota merupakan masyarakat modern dengan berbagai rutinitas dan aktivitas serta mobilitas yang tinggi. Keseharian ini menuntut mereka dengan gaya hidup yang serba cepat serta praktis. Gaya hidup masyarakat kota yang seperti ini sering sekali menuntut mereka untuk menghadapi suatu pekerjaan dan kegiatan yang begitu menyita waktu sehingga dapat membuat mereka lupa akan kebutuhan lainnya termasuk istirahat. Penelitian ini memiliki tujuan untuk menjawab kebutuhan masyarakat, terutama masyarakat Meruya yang merupakan salah satu daerah transisi antara kota Jakarta dan Tangerang melalui peran ruang arsitektur dalam menciptakan ruang untuk beristirahat dan relaksasi ditengah kepadatan aktivitas yang dijalani. Dalam penelitian ini, metode yang digunakan adalah; pertama, melakukan studi, observasi dan penyebaran kuesioner sebagai pengumpulan data awal; kedua, mempelajari dan meninjau kebutuhan dari masyarakat sekitar serta kebutuhan untuk melepas kejenuhan dan beristirhat ditengah aktivitas yang padat; ketiga, menyusun program sesuai dengan hasil survei, observasi serta menjawab kebutuhan masyarakat sehingga tujuan proyek akan tercapai.
\end{abstract}

Kata kunci: aktivitas; arsitektur; istirahat; relaksasi

\begin{abstract}
Urban citizen is a modern society with a wide range of routine, activity, and high mobility. This life demand them to follow a fast-paced and practical lifestyle. This urban lifestyle often followed by demanding workload and activities that are time consuming that they usually forgot about their own primary needs, and one of them is to rest. This research are aimed to answer the needs of the residence who are living under such life, which is the residence of Meruya. Meruya holds the record of being one of the busiest area with high mobility people from Jakarta and Tangerang. Methods that were used in study are conducting studies, observation and giving out online questionnaire as pleminary data collection. To strengthen the pleminary data, studying and reviewing a few resident of Meruya to help finding them a better way for them to still be able to have a calm mind admist their busy life. The results were then processed into architectural programs that hopefully may answer the needs of the resident of Meruya.
\end{abstract}

Keywords: activity; architecture; relaxation; rest

\section{PENDAHULUAN \\ Latar Belakang}

Di zaman yang serba canggih dengan rutinitas yang berkepanjangan dan tanpa henti, terkadang manusia disibukkan dengan kegiatan yang harus ia lakukan. Masyarakat khususnya di kota merupakan masyarakat modern dengan berbagai rutinitas dan aktivitas serta mobilitas yang tinggi. Keseharian ini menuntut mereka dengan gaya hidup yang serba cepat serta praktis. Gaya hidup masyarakat kota yang seperti ini sering sekali menuntut mereka untuk menghadapi suatu pekerjaan dan kegiatan yang begitu menyita waktu sehingga dapat membuat mereka lupa akan kebutuhan hidup seperti makan, minum, tidur, bahkan hingga akhir pekan masyarakat kota menggunakan waktu mereka untuk menyelesaikan pekerjaan. Kondisi ini membuat mereka 
tidak memiliki waktu luang untuk beristirahat dan berlibur. Kegiatan yang demikian pada awalnya tidak memberikan efek apapun pada diri kita, namun seiring berjalannya waktu kejenuhan itu pasti akan muncul. Ketika hal itu terjadi manusia biasanya menanggapinya dengan cara menyelipkan kegiatan lain di sela-sela rutinitasnya tanpa merugikan kegaiatan utama mereka.

\section{Rumusan Permasalahan}

Berdasarkan identifikasi masalah diatas, maka dapat dirumuskan beberapa masalah utama yang menjadi fokus penelitian pada proyek ini, yaitu:

- Bagaimana arsitektur mampu memecahkan permasalahan akan kebutuhan relaksasi di tengah masyarakat kota yang memiliki aktivitas yang padat?

- Bagaimana program arsitektur mampu menyediakan tempat relaksasi yang sekaligus berfungsi sebagai third place bagi masyarakat sekitar?

\section{Tujuan}

- Menjadikan Chil-lax sebagai tempat beristirahat masyarakat kota khususnya Meruya Utara;

- Menjadikan Chil-lax sebagai third place yang interaktif dan positif dalam mewadahi kegiatan masyarakat;

- Merancang tempat yang bersifat relaksasi sehingga dapat menjawab kebutuhan masyarakat akan kebutuhan istirahat di tengah aktivitas mereka yang padat.

\section{KAJIAN LITERATUR}

\section{Third Place}

Menurut Oldenburg (1989) menjelaskan bahwa third place merupakan sebuah lingkungan sosial yang terpisah dari dua lingkungan lainnya, yaitu rumah (first place) dan tempat bekerja (second place). Dimana third place ini merupakan sebuah wadah kehidupan komunitas yang memfasilitasi serta mendorong terjadinya interaksi yang lebih luas dan kreatif. Third place juga merupakan sebuah tempat di mana semua orang dapat datang untuk melakukan berbagaimacam kegiatan mulai dari bersantai hingga berjumpa denglan orang baru.

Beberapa kriteria dari third place:

- Neutral ground: Pengunjung bebas mengakses tempat tanpa hambatan apapun

- Leveler (a leveling place): Tidak terikat dengan status sosial.

- Conversation is the main activity: Pembicaraan yang menyenangkan antar individu

- Accessibility and accommodation: Dapat memenuhi kebutuhan penggunanya

- The regulars: Pengunjung lama dapat menarik pengunjung baru

- A low profile: Tidak mahal dan sederhana

- $\quad$ The mood is playful: Memiliki sifat yang menyenangkan

- A home away from home: Spiritual regeneration

\section{Waktu Luang}

Dalam bahasa inggris waktu luang lebih dikenal dengan sebutan leisure. Kata leisure ini sendiri berasal dari bahasa Latin yaitu licere yang berarti diizinkan (To be Permited) atau menjadi bebas (To be Free). Leisure juga memiliki kata lain yaitu loisir yang berasal dari bahasa Perancis yang artinya waktu luang (Free Time), George Torkildsen (Januarius Anggoa, 2011).

Menurut Gold (1980) dalam bukunya Recreation Planning and Design, disebutkan bahwa dalam satu hari terdapat tiga penggunaan waktu yaitu:

- Subsistance Time, dimana waktu yang digunakan untuk melakukan kebutuhan hidup seharihari seperti makan, minum, tidur; 
- Existance Time, yaitu waktu yang digunakan untuk melakukan pekerjaan yang berhubungan dengan profesi seperti bekerja atau belajar;

- Leisure Time yaitu waktu luang yang digunakan untuk melakukan aktivitas di luar aktivitas existance dan subsistence.

\section{Manfaat Mengisi Waktu Luang}

- Beberapa manfaat penting waktu luang yang dapat diperoleh jika mengisi waktu luang dengan baik yaitu:

- $\quad$ Bisa meningkatkan kesejahteraan jasmani;

- Meningkatkan kesegaran mental dan emosional;

- Membuat kita mengenali kemampuan diri sendiri;

- Mendukung konsep diri serta harga diri;

- Sarana belajar dan pengembangan kemampuan;

- Pelampiasan ekspresi dan keseimbangan jasmani, mental, intelektual, spiritual, maupun estetika;

- Melakukan penghayatan terhadap apa yang disukai tanpa mempedulikan segi materi.

\section{Kegiatan Waktu Luang}

Berdasarkan dari definisi di atas dapat diketahui baha waktu luang merupakan waktu yang digunakan untuk melakukan berbagai macam aktivitas baik untuk beristirahat, menghibur diri setelah melepas diri dari segala pekerjaan rutinnya yang padat. Beberapa kegiatan mengisi wakru luang diantaranya:

\section{a. Kegiatan Relaksasi (Relaxation Activity)}

Menurut Soetarlinah Sukadji (Triatmoko, 2007) relaksasi terbagi menjadi dua macam yaitu relaksasi aktif dan pasif.

- Relaksasi aktif

Melakukan kegiatan yang bersifat produktif, cenderung meningkatkan ketrampilan harga diri. Contohnya: memperbaiki motor, khursus memasak, dan lain-lain;

- Relaksasi Pasif

Kegiatan yang melibatkan sedikit indra. Contohnya: menonton mendengarkan music, membaca buku, dan lain-lain.

b. Kegiatan Hiburan (Entertainment Activity)

Menurut Fine, Mortimer, \& Robert (Broderick \& Blewitt, 2006), kegiatan relaksasi dapat meningkatkan ketrampilan, seperti olahraga, hobi, dan kesenian atau yang lebih umum seperti bermain video game, melamun atau nongkrong dengan teman-teman.

\section{RELAKSASI}

dapat diartikan sebagai teknik yang dilakukan untuk mengatasi stres dimana akan terjadi peningkatan aliran darah sehingga perasaan cemas dan khawatir akan berkurang (Abbasi et al, 2018). Relaksasi merupakan proses merilekskan otot-otot yang mengalami ketegangan atau mengendorkan otot-otot tubuh dan pikiran agar tercapai kondisi yang nyaman atau berada pada gelombang otak alfa-teta (Yunus, 2014).

\section{Manfaat Relaksasi}

Manfaat relaksasi secara umum:

- Relaksasi dapat membuat seseorang lebih mampu menghindari reaksi berlebih akibat stress;

- Masalah-masalah yang timbul akibat stres seperti sakit kepala, tekanan darah tinggi, insomnia, dan perilaku-perilaku buruk dapat berkurang; 
- Meningkatkan hubungan interpesonal dan harga diri pada seseorang;

- Meningkatkan semangat pada seseorang dalam melakukan aktivitas;

- Mengurangi tingkat kecemasan pada seseorang dan memunculkan efek disiologis yang positif;

- Meningkatkan produktivitas kerja.

\section{Jenis -jenis relaksasi}

Menurut Miltenberger (2004) relakasasi dibedakan menjadi empat macam yaitu relaksasi otot (progressive muscle relaxation), relaksasi pernafasan (diaphragmatic breathing), relaksasi dengan cara meditasi (attention focussing exercises), dan relaksasi perilaku (behavioural relaxation training) dan lain sebagainya.

\section{METODE}

\section{Penjelasan Metode}

Metode yang dilakukan penulis dalam melakukan perancangan perancangan adalah metode deskriptif dengan memaparkan atau mengidentifikasi data-data yang diperoleh serta melakukan komparasi dengan studi literatur yang mendukung teori untuk memperoleh program dasar serta peluang kombinasi dari program tersebut.

\section{Pengumpulan dan pengolahan data}

Pengumpulan data merupakan tahapan metode perancangan yang sangat penting, karena perancangan akan berjalan lancar apabila data-data yang diperlukan sudah ada dan lengkap. Pengumpulan data ini dilakukan untuk mendapatkan data-data baik secara primer maupun sekunder.

\section{Data primer}

\section{- Kuesioner}

Kuesioner merupakan metode pengumpulan data yang dilakukan dengan cara memberi seperangkat pertanyaan atau pernyataan tertulis kepada responden untuk dijawab. Kuesioner merupakan metode pengumpulan data yang lebih efisien bila peneliti telah mengetahui dengan pasti variabel yag akan diukur dan tahu apa yang diharapkan dari responden. Selain itu kuesioner juga cocok digunakan bila jumlah responden cukup besar dan tersebar di wilayah yang luas;

- Observasi

Observasi adalah suatu kegiatan yang dilakukan dengan mengamati dan mencatat secara sistematis terhadap gejala atau fenomena yang diselidiki. metode observasi dapat diartikan sebagai pencatatan sistematika fenomena yang diselidiki. Dengan melakukan observasi akan mendapatkan data atau informasi-informasi yang terkait dengan apa saja yang di butuhkan masyarakat sekitar;

- Dokumentasi

Dokumentasi merupakan metode yang digunakan untuk mencari data yang diperlukan berdasarkan peristiwa yang ada. Dokumentasi ini dilakukan dengan cara mendokumentasikan tapak perancangan dan daerah sekitarnya.

\section{Data Sekunder}

Data sekunder yaitu data atau informasi yang tidak berkaitan secara langsung dengan obyek perancangan tetapi sangat mendukung program perancangan. Tujuan dari studi pustaka adalah untuk mendapatkan data-data yang dibutuhkan, baik dari teori, pendapat ahli, serta peraturan dan kebijakan pemerintah yang dapat dijadikan dasar perencanaan sehingga dapat memperdalam analisa. 


\section{DISKUSI DAN HASIL}

\section{Analisis Lokasi}

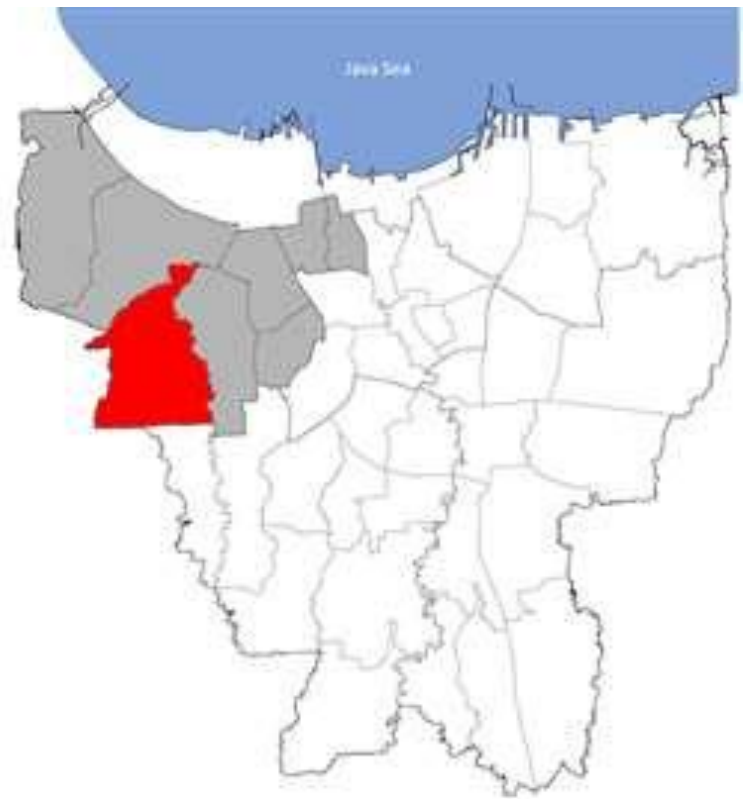

Gambar 1. Kecamatan Kembangan

Sumber : https://id.wikipedia.org/wiki/Kembangan,_Jakarta_Barat

Kecamatan Kembangan merupakan kawasan Sentral Primer Barat yang memiliki potensi ekonomi yang besar. Kecamatan kembangan memiliki wilayah seluas $25,37 \mathrm{~km}^{2}$ ini merupakan pusat pemerintahan dari kota administrasi Jakarta Barat sehingga terdapat berbagai kantor-kantor pemerintahan seperti Kantor Walikota Jakarta Barat, Kantor Kejaksaan Negri Jakarta Barat, dan Pengadilan Agama Jakarta Barat. Selain memiliki kantor-kantor pemerintahan, kecamatan ini juga termasuk dalam Kawasan Sentral Primer Barat yang memiliki potensi ekonomi yang besar, Kecamatan Kembanagn juga merupakan kecamatan dengan tingkat pertumbuhan penduduk tertinggi di wilayah Jakata Barat.

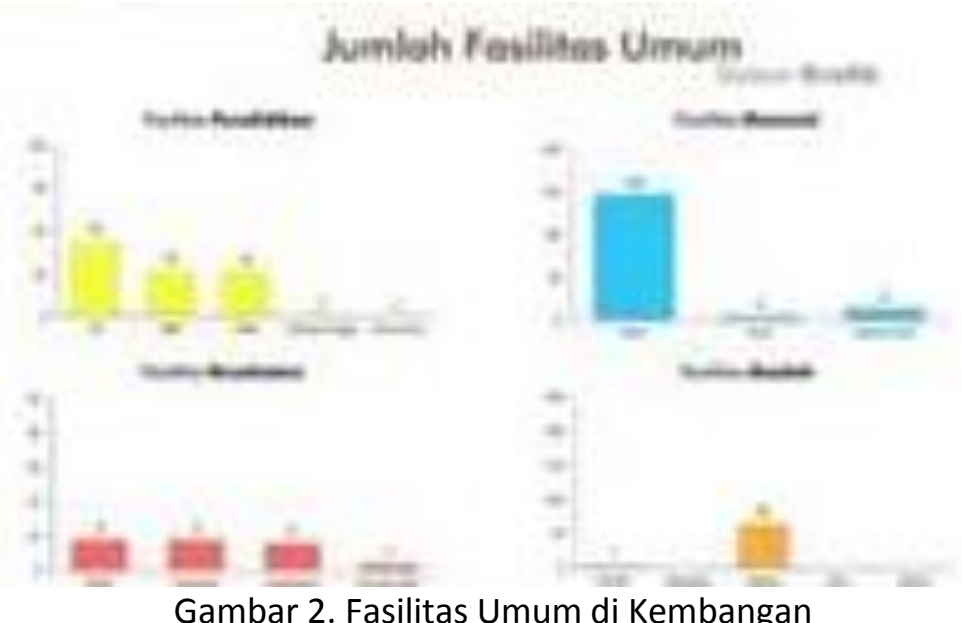

Sumber: https://openstreetmap.id/peta-kelurahan-kelurahan-di-jakarta-barat/ 


\section{Meruya Utara}

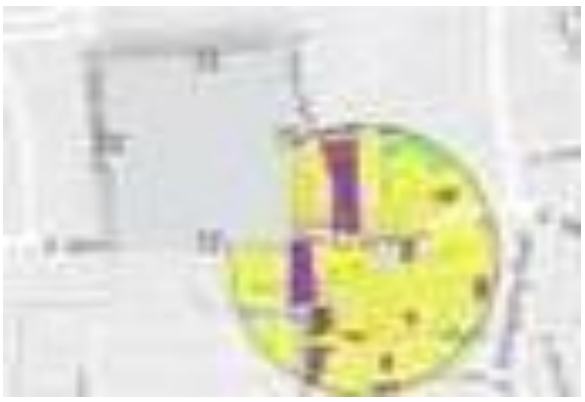

Gambar 3. Zonasi Tapak

Sumber: https://www.google.com/maps/place/Meruya+Utara dan diedit oleh penulis.

- Merupakan salah satu bagian dari kecamatan kembangan di mana Kelurahan ini berbatasan dengan Kembangan Selatan di sebelah utara, Karang Tengah di sebelah barat, Kebon Jeruk di sebelah timur dan Srengseng dan Meruya Selatan di sebelah selatan;

- Berdasarkan letak lokasinya Meruya Utara merupakan daerah transisi antara Kota Jakarta dan Tangerang;

- Tapak berlokasi di Jl. Meruya Lilir Raya, Jakarta Barat dengan data: KDB : 60\%, KLB: 1.2, KTB: 0, KB: 2, KDH: 20\%, TIPE : K.

\section{Potensi Tapak}

Kawasan yang dipilih untuk proyek kali ini memiliki beberapa peluang diantaranya:

- Lokasi strategis;

- mudah dijangkau baik dengan transportasi umum maupun dengan trasportasi pribadi, infrastruktur yang memadai;

- Merupakan daerah transisi antara kota Jakarta dan Tangerang, sehingga sasaran proyek dapat tercapai yaitu untuk masyarakat Meruya dan sekitarnya;

- Merupakan kawasan Sentral Primer Barat yang memiliki potensi ekonomi yang besar.

\section{Moda Transportasi}

Lokasi tapak dapat dicapai dengan cara:
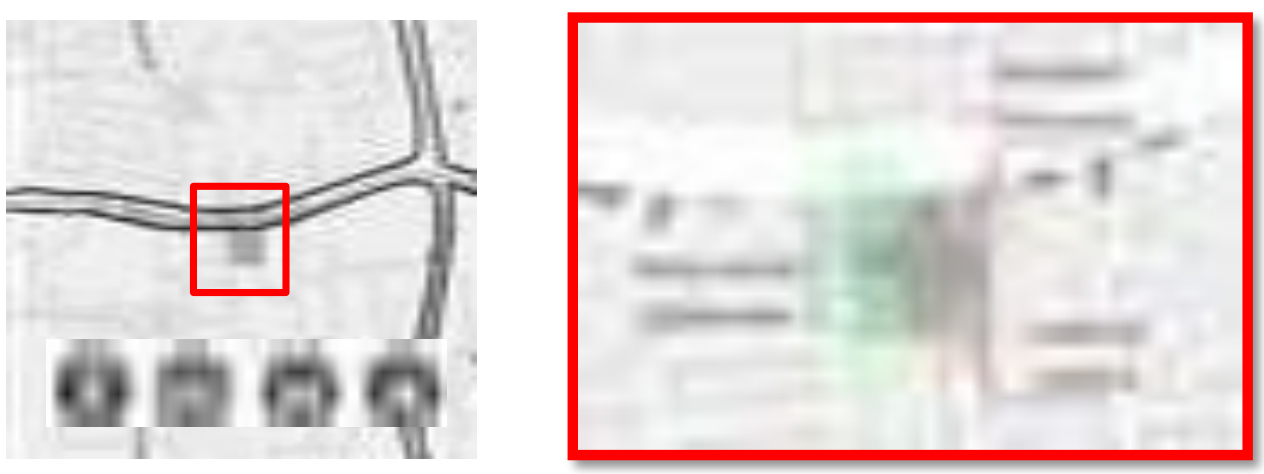

Gambar 4. Jalur menuju tapak

Sumber: https://www.google.com/maps/place/Meruya+Utara dan diedit oleh penulis.

- berjalan kaki;

- transportasi umum dan pribadi.

Dari gambar diatas dapat disimpulkan bahwa tapak dapat dicapai dengan cara berjalan kaki maupun dengan kendaraan pribadi dan umum sehingga zona masuk pada tapak di bagi 
menjadi dua bagian yaitu zona khusus pejalan kaki dan zona untuk kendaraan sehingga tidak terjadi crossing antara pejalan kaki dan kendaraan.

Tapak dilewati berbagai macam transportasi umum mulai dari transjakarta, mikrolet, bus dalam kota, hingga angkot.

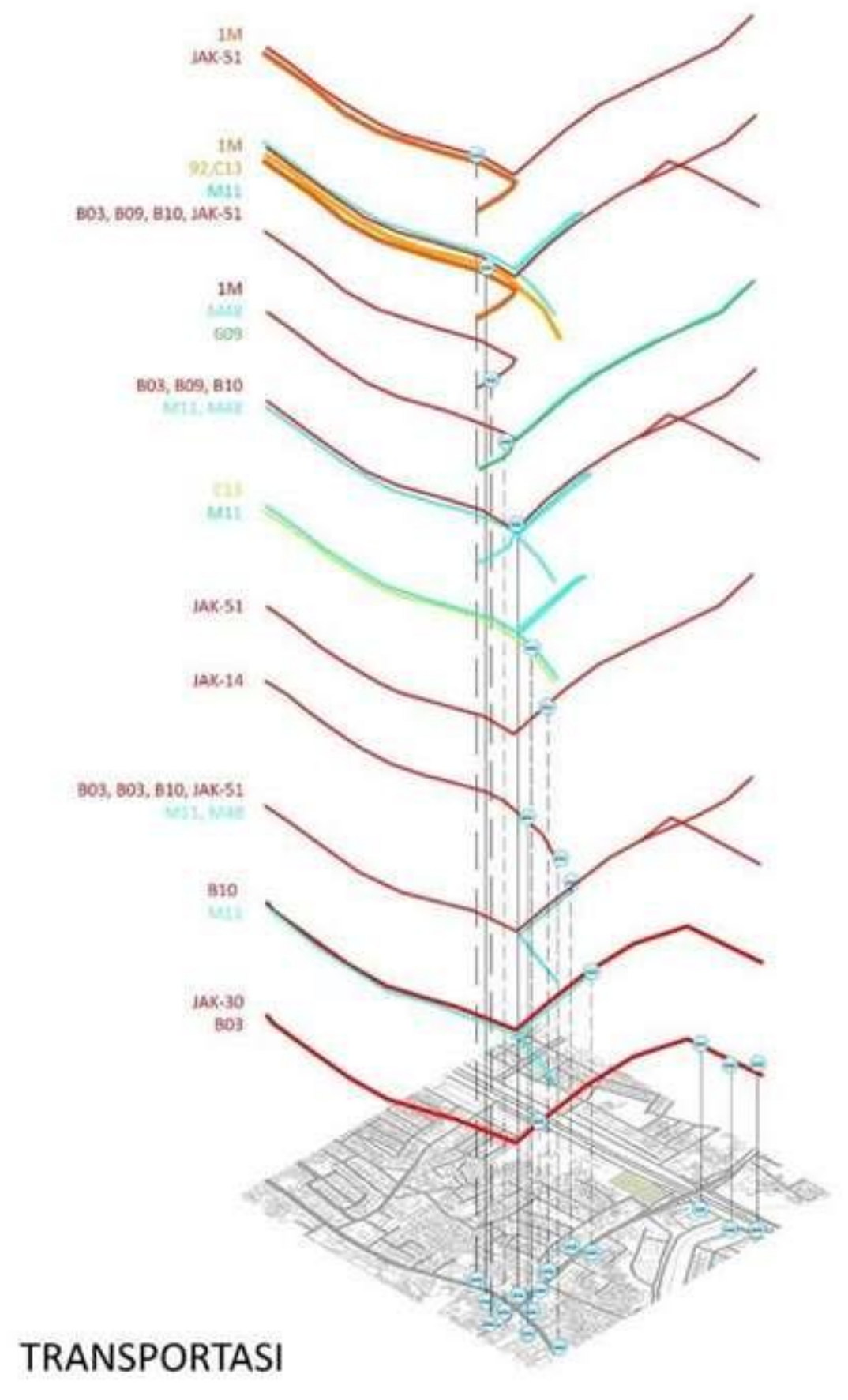

Gambar 5. Jalur Transportasi umum

Sumber: https://www.google.com/maps/place/Meruya+Utara dan diedit oleh penulis 


\section{Kepadatan Lalulintas}

Kepadatan lalu lintas di tapak pada weekend saat pagi hari dimulai dari jam 08.00-11.00 WIB dan saat sore hali dimulai dari jam 16.00-21.00 WIB dan Kepadatan lalu lintas di tapak pada weekday saat dimulai dari jam 07.00-21.00 WIB.
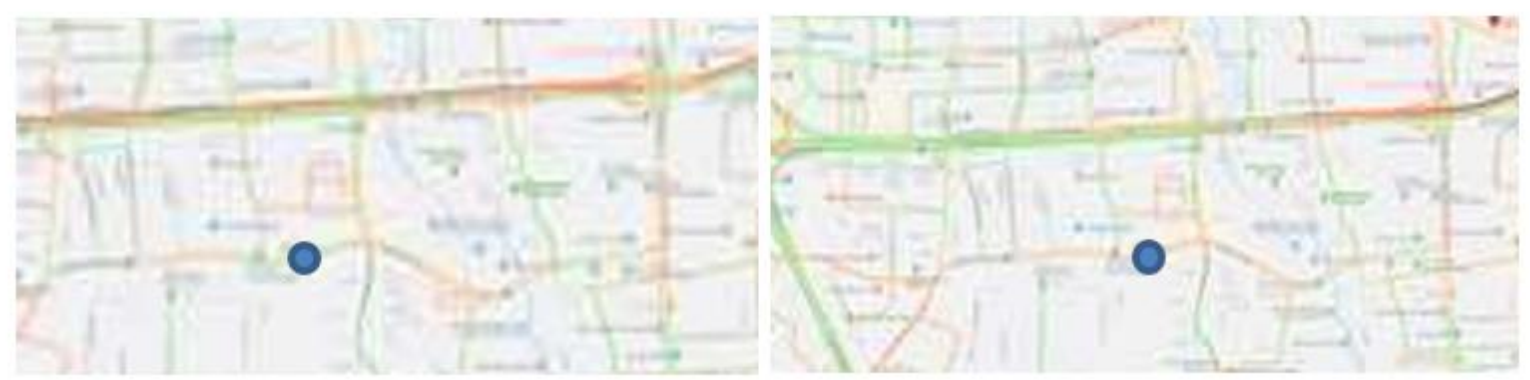

Kepadatan lalulintas jam 08.00-11.00 WIB
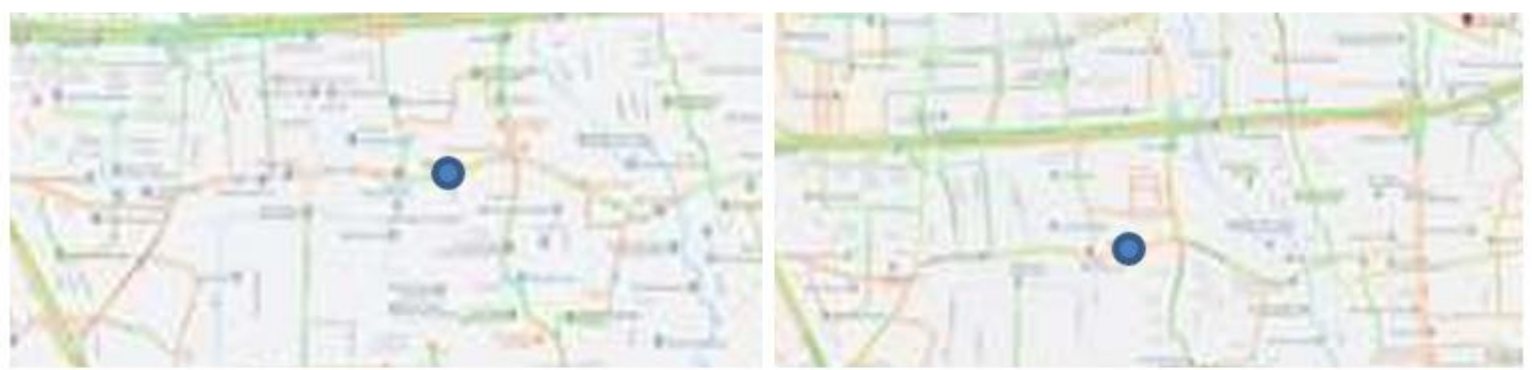

Kepadatan lalulintas jam 16.00-21.00 WIB
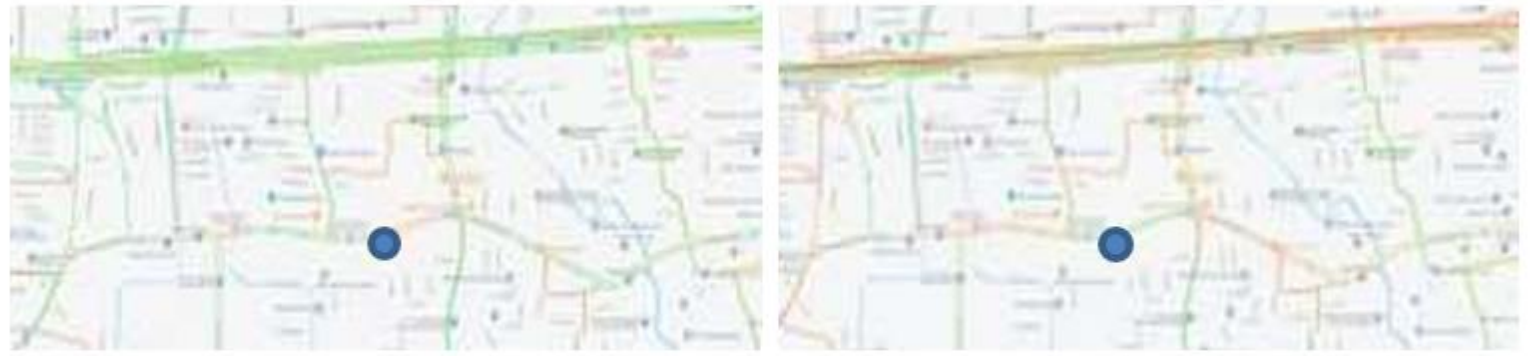

Kepadatan lalulintas jam 16.00-21.00 WIB

Gambar 6. Kepadatan lalulintas saat weeday dan weekend

Sumber: https://www.google.com/maps/place/Meruya+Utara dan diedit oleh penulis

\section{Analisis konsep dan Program Kegiatan}

Masyarakat kota terkenal akan kesibukannya tak terkecuali masyarakat meruya dimana aktivitas yang menjadi rutinitas utama mereka adalah bekerja. Ketika mereka berangkat bekerja mereka cenderung terburu-buru sehingga mereka membutuhkan sesauatu kegiatan yang bersifat cepat, tepat, namun tetap dapat membuat mereka tenang. Sedangkan ketika mereka pulang cenderung membawa stres sehingga mereka membutuhkan sesuatu kegiatan yang bersifat menyenangkan, menenangkan, dan membuat mereka merasa aman. Sehingga terbentuklah 6 kata kunci yaitu fun, secure, relax, chill, precise, and quick. 


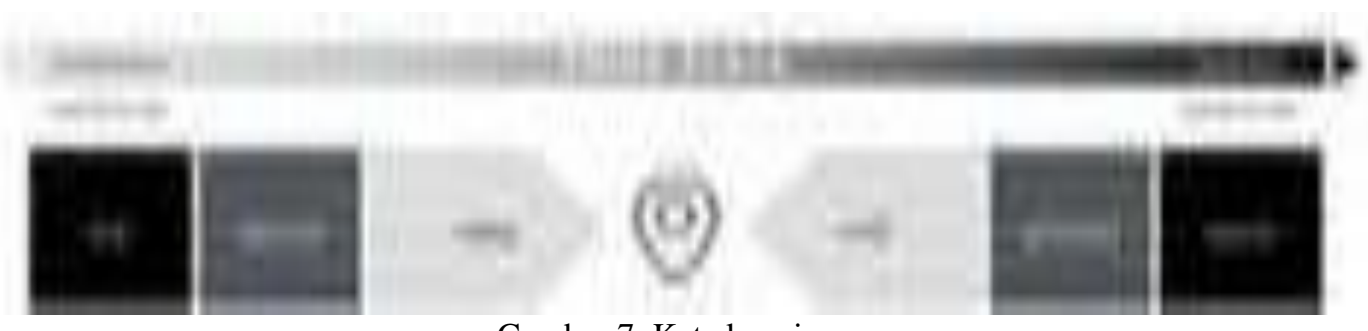

Gambar 7. Kata kunci

Dari ke enam kata kunci di atas dittitik beratkan pada kata chill and relax yang kemudian dijadikan sebagai dasar pembentukan program Kegiatan, sehingga menghasilkan program sebagai berikut:

- Fun and Quick : :Game are, outdoor chinema, fitness and Gym;

- $\quad$ Secure and Precise : sharing area, restaurants, workshop;

- Relax and Chill : live music, bar, massage and reflexiology, cafe, karaoke.

Hasil dari program tersebut kembali di klompokan sehingga terbentuk 4 program utama yaitu:

- Sportainment : Fitness and Gym, and massage and reflexiology;

- Social :Workshop, and sharing area;

- Leisure : : Outdoor chinema, game area, karaoke, live music;

- F\&B : Bar, café, restaurant.

\section{Bentuk Rancangan}

Bentuk dasarv bangunan berasal dari bentuk aksis tapak, yang kemudian dipisah menjadi dua bagian berdasarkan hasil dari analisa tapak, selanjutnya masa yang sudah terpisah menjadi dua bagian diangkat keatas berdasarkan pemenuhan program yang ada, lalu pada bagian atas kembali dipisah menjadi empat bagian berdasarkan zoning yang ada dan terakhir masa dititik beratkan di bagian tengan bangunan sebagai pusat dan titik temu dari bangunan.
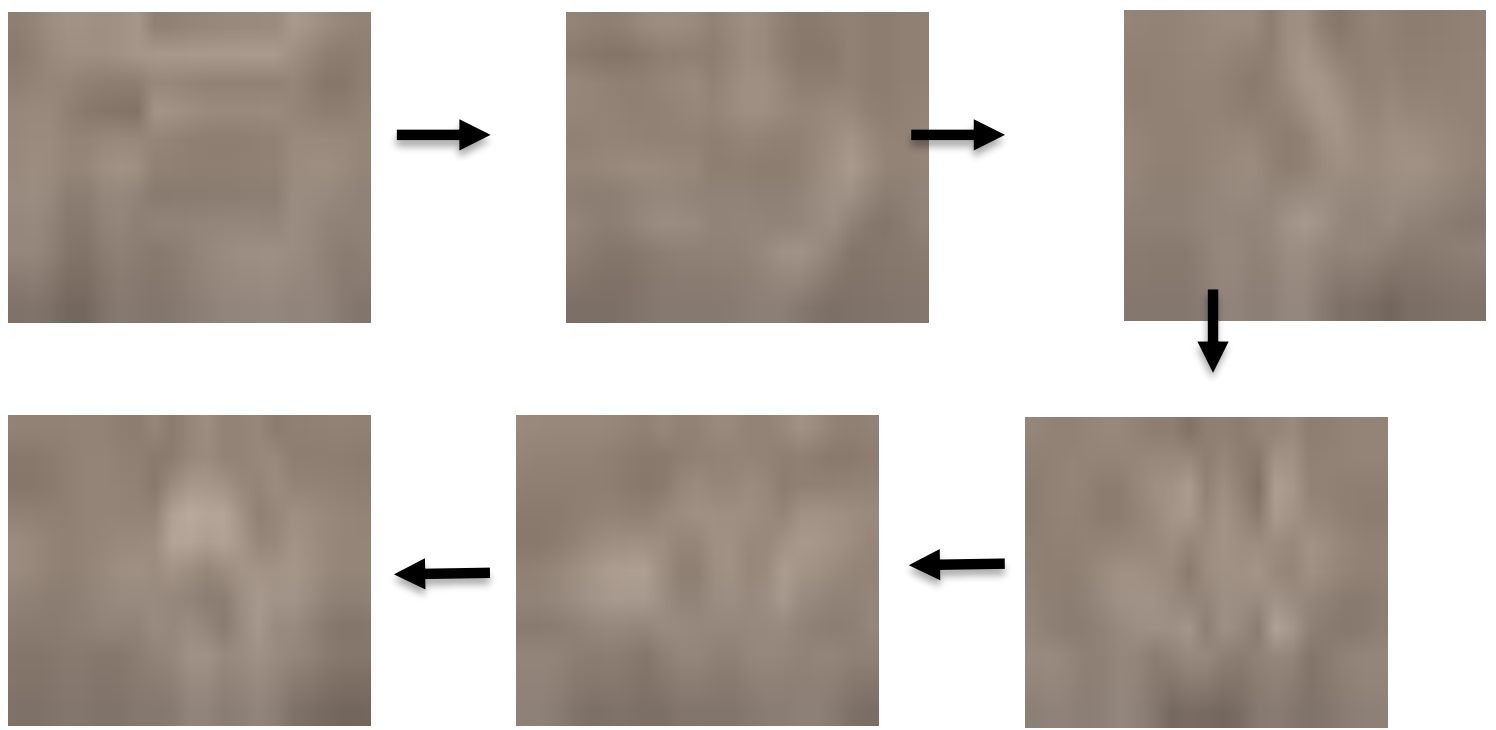

Gambar 8. Proses terbentuknya gubahan 


\section{Hasil}

Chil-lax merupaan sebuah proyek yang memiliki tujuan untuk menjawab kebutuhan masyarakat, terutama masyarakat Meruya yang merupakan salah satu daerah transisi antara kota Jakarta dan Tangerang melalui peran ruang arsitektur dalam menciptakan ruang untuk beristirahat dan relaksasi ditengah kepadatan aktivitas yang dijalani.

Proyek ini memiliki dua kata kunci yaitu chill and relax yang dijadikan dasar dalam perancangan dimana pengunjung dapat datang melalui dua titik yaitu:

\section{Dari arah SPBU}

Pengunjung dari arah SPBU akan disambut oleh area café dan resto pada lantai satu dan dilantai dua terdapat bar dan game area serta tempat karaoke;

\section{Drop Off}

Ketika dari drop Off pengunjung dapat mengakses bangunan di sisi barat dimana pada bangunan tersebut terdapat café dan resto ataupun mengakses bangunan di sisi timur yang terdapat fasilitas sharing area, workshop, dan fitness and gym pada lantai satu serta studio dan area massage and reflexiology di lamtai dua;

- Café dan Restaurant

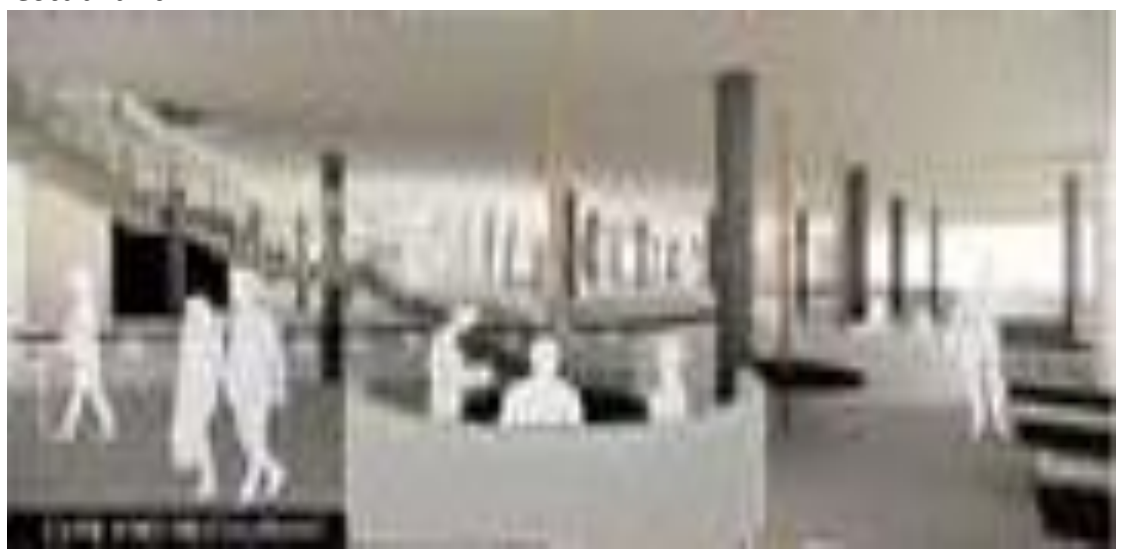

Pada zona ini, café dan resto menawarkan konsep yang berbeda dimana system makan dibuat lebih Playful dimana pengunjung yang datang bebas untuk memilih tepat serta bagaimana cara mereka makan entah itu didalam bangunan, di luar bangunan, lesehan, diatas meja, ataupun di amphitheater. Pada zona ini dibuat pilotis sehingga memiliki view ke outdoor chinema dan taman depan sehingga pengunjung yang datang dapat makan sambal menikmati lingkungan sekitar, serta bagi pengunjung yang membawa anak tidak perlu khawatir karena mereka dapat melakukan aktivitas makan sambil mengawasi anak mereka yang bermain di taman.

- Sharing area dan workshop

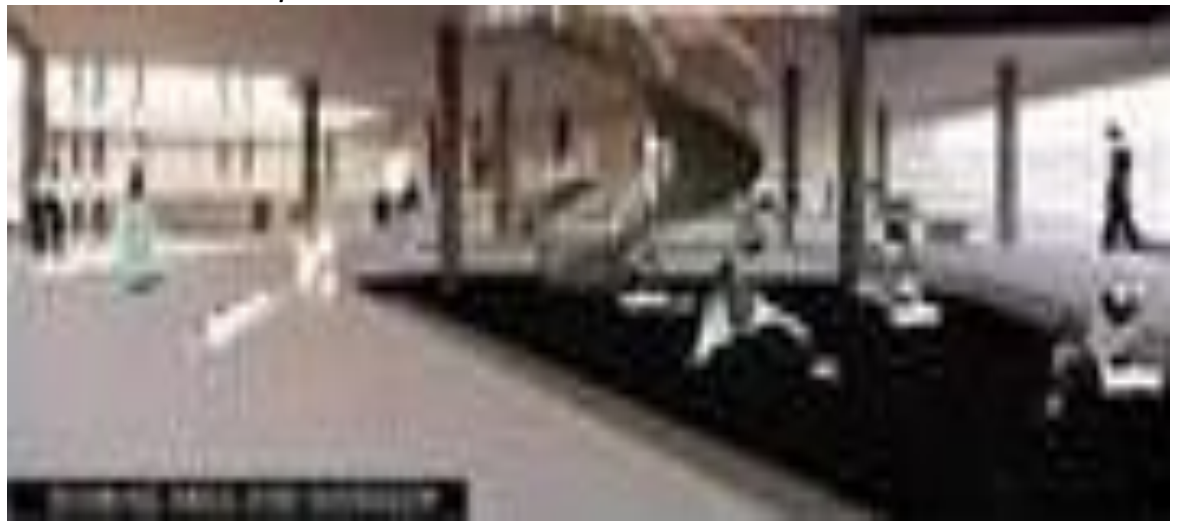


Pada zona ini di desain se-chill and relax mungkin oleh karena itu pada zona ini dibuat pilotis dan terbuka sehingga pengunjung tidak merasa terikat pada satu wilayah/zona tertentu. Pada zona ini pengunjung dapat melakuan berbagai macam aktivitas mulai dari bercengkramah/ngobrol satu sama lain, sharing, mengerjakan tugas sampai mengadakan workshop. Dari Sharing area dan workshop pengunjung dapat mengakses kebawah menuju area outdoor chinema dan live music ataupun keatas menuju fitness and gym area;

- Outdoor Chinema and Live Music

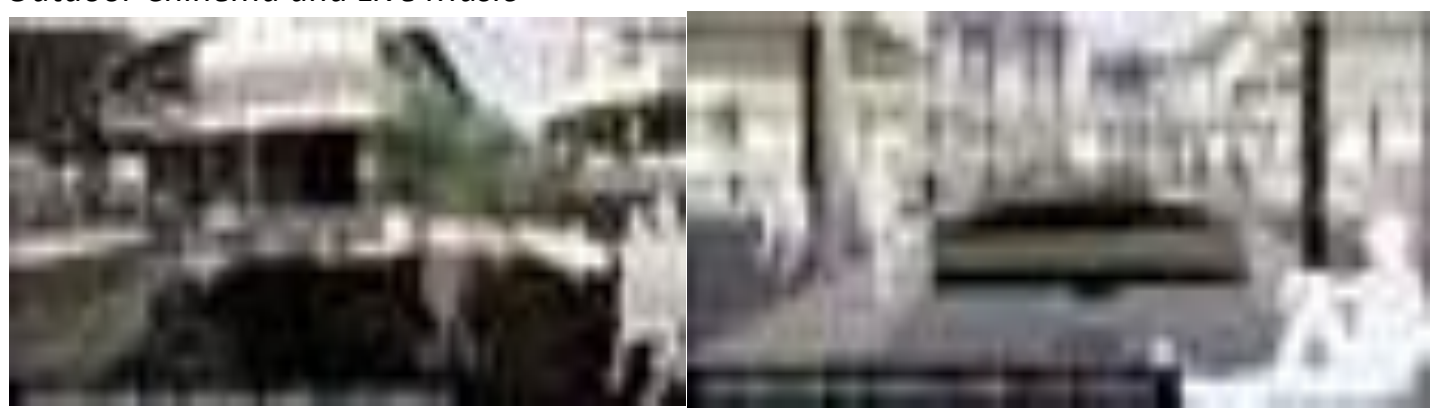

Area ini ditempatkan di tengah bangunan yang menjadi titik ousat dan titik temu dari bangunan seingga pada lantai dua di design memiliki balkon yang dapat menghadap lagsung ke area outdoor chinema hal ini diharapkan agar pengunjung dapat ikut menikmati tayangan yang ada tanpa harus terikat di suatu tempat.

- Fitness \& Gym

Area ini terdiri dari dua lantai dimana pada lantai pertama merupakan tempat olahrag yang menggunakan alat bantu, sedangkan pada lantai dua digunakan sebagai kelas studio untuk kegiatan yoga, taichi, meditasi, dan dance. pada bagian ini terdapat juga pembagian atara yang berbayar dan gratis, dimana yang gratis lebih diperuntukan kepada para pemula dan apabila mereka tertarik dan ingin melanjutkan mereka dapat masuk kekelas lanjutan yang berbayar. Oleh karena itu pada area studio di design transparan dan terbuka agar kelas lanjutan dapat menunjukan kebolehan mereka dan menjadi daya tarik bagi para pemula maupun para pengunjung yang datang.

- Massage and reflexiology

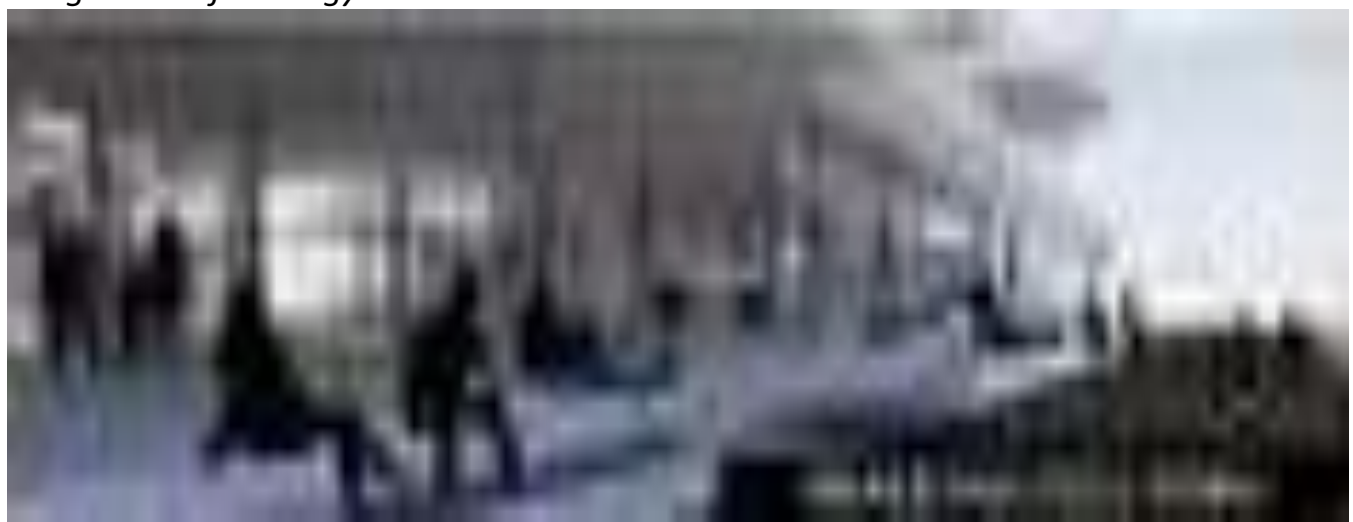

Fasilitas ini terbagi menjadi dua bagian dimana yang berbayar berada di lantai dua pada bangunan sebelah timur yang dapat diakses melalui area fitness and gym ataupun dari area sharing and worksop. Sedangkan yang gratis terdapat di taman bagian timur area sharing and worksop. 
- Bar, game area, dan karaoke

Terdapat di lantai dua pada bangunan sebelah barat dimana game area sebagai pengikat antara bar dan karaoke sehingga aktivitas pengunjung tidak monoton ataupun terfokus pada satu bagian saja.

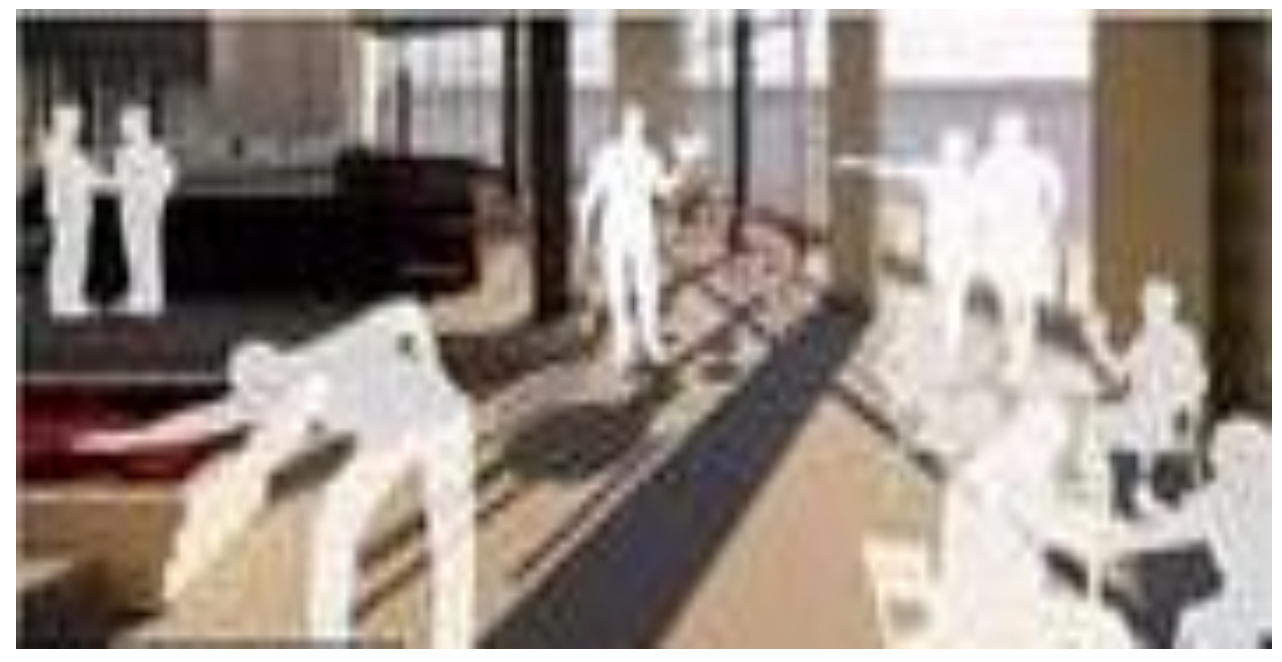

\section{KESIMPULAN DAN SARAN}

Chil-lax merupakan perwujudan dari Third place yang mampu mewadahi kebutuhan masyarakat khususnya di daerah Meruya dengan mengangkat sebuah fenomena yaitu kurangnya waktu istirahat masyarakat Meruya yang diakibatkan oleh padatnya rutinias mereka, yang diharapkan dengan terbentuknya proyek ini masyarakat kota dapat memanfaatkan waktu luang mereka dengan baik dengan memenuhi kebutuhan mereka akan istrahat sehingga dapat meningkatkan kinerja merek adalam melakukanberbagai macam aktivitas.

Berdasarkan kebutuhan tersebut, proyek ini akan memiliki 4 program utama yaitu:

- Sportainment dengan fungsi berupa tempat gym and fitness dan massage and reflexiology;

- Leisure dengan program outdoor cinema, live music, karaoke;

- Social;

\section{REFERENSI}

Abbasi, B., Navid, M., Lella A, O., Askan, I., Samaneh ,H., SeyedMehdi ,T., Shalpar H. (2018). The Effect of Relaxation Techniques on Edema, Anxiety and Depression in Post-Mastectomy Lymphedema Patients Undergoing Comprehensive Decongestive Therapy: A Clinical Trial. Diakses dari. https://doi.org/10.1371/journal.pone.0190231 pada tanggal 10 Desember 2019

Branch, M. C. (1995). perancangan kota komprehensif. Jogjakarta: Gajah Mada University Gold, S. M. (1980). Recreation, Planning and Design. New York: Mc Graw Hill Book Company. Goodale, T. L., dan Geoffrey, G. (1988). The Evolution of Leisure. Inggris Raya: Venture Pub. Januarius, A. (2011). Study Tingkat Kebosanan Dalam Waktu Luang pada Mahasiswa Baru Universitas Kristen Petra Surabaya. Diakses dari http://digilib.petra.ac.id pada tanggal 12 Desember 2019.

Miltenberger, R. G. (2004). Behavior Modification Principles and Procedures (3 th edition). Australia: Thompson Wadsworth.

Oldenburg, R. (1989) The Great Good Place, The Great Good Place.

Seligman, M.E.P., \& Csikszentmihalyi, M. (2000). Positive psychoology: an introduction. Journal of American Psychologist, Vol. 55 (1), page 5-14.

Torkildsen, G. (1992). Leisure and recreation management. London: E \& EN spon. 
Triatmoko. (2007). Mengisi Celah Waktu Luang. Diakses dari http://popsy.wordpress.com. pada tanggal 5 juli 2010 
